\title{
Conectividade e compartimentação dos sistemas aqüíferos Serra Geral e Guarani no sudoeste do estado do Paraná, Brasil
}

\author{
Roderlei Cleber Mocellin ${ }^{1}$ \& Francisco José Fonseca Ferreira ${ }^{1,2}$
}

\begin{abstract}
Resumo Na região estudada, situada entre as coordenadas $53^{\circ} 00^{\prime} / 54^{\circ} 30^{\prime} \mathrm{W}$ e $24^{\circ} 30^{\prime} / 26^{\circ} 12^{\prime} \mathrm{S}$, sudoeste do Estado do Paraná, dominam derrames basálticos da Formação Serra Geral (Sistema Aquífero Serra Geral - SASG), os quais estão sobrepostos as formações Botucatu/Pirambóia (Sistema Aquífero Guarani - SAG). A aplicação combinada de dados aeromagnetométricos, geológicos, estruturais (MDE, rede de drenagem e imagens de satélite), hidrogeológicos e hidroquímicos, permitiu averiguar o controle estrutural do fluxo e do quimismo das águas subterrâneas do SASG (fissural). Também se buscou interpretar, com base na hidroquímica do SASG e no arcabouço estrutural, zonas de falhas sugestivas de conexão hidráulica com o SAG (granular). A interpretação dos dados aeromagnetométricos e sua integração geológica permitiram delinear um arcabouço magnético-estrutural da área de estudo, caracterizado por tendências nas direções NW-SE, NE-SW e E-W. Tal arcabouço foi cotejado à distribuição espacial de parâmetros hidrogeológicos (potenciometria, vazão e capacidade específica de exploração - 181 poços) e hidroquímicos ( $\mathrm{pH}$, sólidos totais dissolvidos, cálcio, magnésio, sódio, potássio, bicarbonato, carbonato, cloreto e sulfato - 100 poços). Todos os poços foram completados na Formação Serra Geral. Os resultados hidroquímicos mostraram a predominância de águas bicarbonatadas cálcicas, seguidas das bicarbonatadas sódicas, mistas, magnesianas e sulfatadas sódicas. As águas bicarbonatadas cálcicas e magnesianas foram consideradas típicas do SASG, enquanto as demais foram interpretadas como reflexo de diferentes taxas de mesclagem com águas provenientes de aqǘferos sotopostos, principalmente do SAG. A interpretação integrada permitiu reconhecer o controle estrutural dos dados hidrogeológicos e hidroquímicos e sugerir zonas de conexão hidráulica dos SASG e SAG.
\end{abstract}

Palavras-chave: Sistema Aquífero Serra Geral, Sistema Aquífero Guarani, conexão hidráulica, aeromagnetometria, Bacia Paraná.

\begin{abstract}
Connectivity and compartimentation of the Serra Geral and Guarani aquifers systems in the southwest of the Paraná state, Brazil. This study was conducted in the southwest portion of the State of Paraná $\left(53^{\circ} 00^{\prime} / 54^{\circ} 30^{\prime} \mathrm{W}\right.$ and $\left.24^{\circ} 30^{\prime} / 26^{\circ} 12^{\prime} \mathrm{S}\right)$, where basaltic lava flows from the Serra Geral Formation (Serra Geral Aquifer System - SGAS) predominate and are superimposed to the Botucatu/Pirambóia formations (Guarani Aquifer System - GAS). It shows the combined application of aeromagnetic, geological, structural (MDE, drainage system and satellite images), hydrogeological and hydrochemical data with the purpose of investigating the structural control and chemical properties of the SGAS (fractured). It also aimed to interpret, based on the hydrochemical properties of the SGAS and its structural outline, fractures that may represent zones of hydraulic connection between this aquifer and the GAS (granular). The aeromagnetic and orbital data integration allowing the composition of a magnetic-structural framework of the study area. Such framework, characterized by tendencies in the NW-SE, NE-SW and E-W directions, was compared to the spatial distribution of hydrogeological (potentiometry, outflow and specific capacity of exploitation - 181 wells) and hydrochemical parameters ( $\mathrm{pH}$, total dissolved solids, calcium, magnesium, sodium, potassium, bicarbonate, carbonate, chlorate and sulfate - 100 wells). All information of wells drilled were from SGAS. The hydrochemical results showed that calcium bicarbonated waters are more common, followed by sodium bicarbonated waters, mixed, magnesian and sulfated sodic. Calcium bicarbonated waters and magnesian were considered typical of the SASG, while the others were interpreted as a consequence of different levels of mixing with waters from other underlying aquifers.e integrated interpretation allowed for the recognition of the structural control of different levels of mixing with waters from other underlying aquifers.
\end{abstract}

Keywords: Serra Geral Aquifer System, Guarani Aquifer System, hydraulic connection, aeromagnetometry, Paraná Basin.

1 - UFPR, Programa de Pós-Graduação em Geologia, Curitiba (PR), Brasil. E-mail: r.clebermocellin@gmail.com

2 - UFPR, Departamento de Geologia, Laboratório de Pesquisas em Geofísica Aplicada/LPGA, Curitiba (PR), Brasil. E-mail: francisco. ferreira@ufpr.br 
INTRODUÇÃOO O Sistema Aqǘfero Serra Geral (SASG - fissural), composto por derrames basálticos da Formação Serra Geral (Cretáceo Inferior), está sobreposto ao Sistema Aqüífero Guarani (SAG - granular), na Bacia do Paraná, o qual encerra predominantemente arenitos das formações Pirambóia e Botucatu (Triássi$\mathrm{co} /$ Jurássico). Tendo em vista o arcabouço estrutural da Bacia do Paraná (e.g. Zalán et. al. 1991), Araújo et al. (1995) consideraram que os regimes hidrogeológicos são distintos nos vários compartimentos que a compõem, em geral caracterizados por blocos romboédricos limitados por tendências NW e NE, do que decorre uma segmentação do padrão de fluxo a partir das zonas de recarga. Por outro lado, a detecção de padrões hidroquímicos anômalos no SASG, não condizentes com a composição química dos basaltos típicos, levou vários autores a interpretar tais padrões com base em misturas de águas de aqüíferos sotopostos, principalmente do SAG (e.g. Bittencourt 1978, Rosa Filho et al. 1987; Buchmann Filho 2002, Bittencourt et al. 2003). Posteriormente, outros autores buscaram relacionar o arcabouço estrutural e o quimismo das águas do SASG, visando sugerir zonas de fraqueza supostamente responsáveis pela conectividade hidráulica dos referidos sistemas aqǘfferos (e.g. Rosa Filho et al. 2003, Ferreira et al. 2004, Portela Filho et al. 2005, Ferreira et al. 2005, Silva 2007). Na continuidade desta linha de pesquisa, foi selecionada uma área situada na porção Sudoeste do Estado do Paraná, limitada pelas coordenadas geodésicas $53^{\circ} 00^{\prime}$ e $54^{\circ} 30^{\prime}$ de longitude Oeste e $24^{\circ} 30^{\prime}$ e $26^{\circ} 12^{\prime}$ de latitude Sul (Fig. 1), cujos resultados são apresentados neste trabalho.

\section{CONTEXTO TECTÔNICO E GEOLOGIA DA} ÁREA DE ESTUDO A área de estudo faz parte da Bacia do Paraná, a qual se distribui pelo centro-Sul do Brasil $\left(1,1 \times 10^{6} \mathrm{~km}^{2}\right)$, Leste do Paraguai $\left(1,0 \times 10^{5} \mathrm{~km}^{2}\right)$, Nordeste da Argentina $\left(4,0 \times 10^{5} \mathrm{~km}^{2}\right)$ e Norte do Uruguai $\left(1,0 \times 10^{5} \mathrm{~km}^{2}\right)$, ocupando uma área aproximada de $1,7 \times 10^{6} \mathrm{~km}^{2}$ do centro-Sudeste da América do Sul. Seu registro estratigráfico iniciou no Neo-Ordovinciano $( \pm$ $450 \mathrm{Ma}$ ), com as primeiras incursões marinhas, passando por estágios de glaciação no Neo-Carbonífero e desertificação do interior continental no intervalo Triássico-Jurássico, registrando um importante evento magmático Mesozóico, até o encerramento da sedimentação no Neo-Cretáceo ( $\pm 65 \mathrm{Ma})$. Neste intervalo de cerca de 390 Ma, estão registrados na Bacia do Paraná

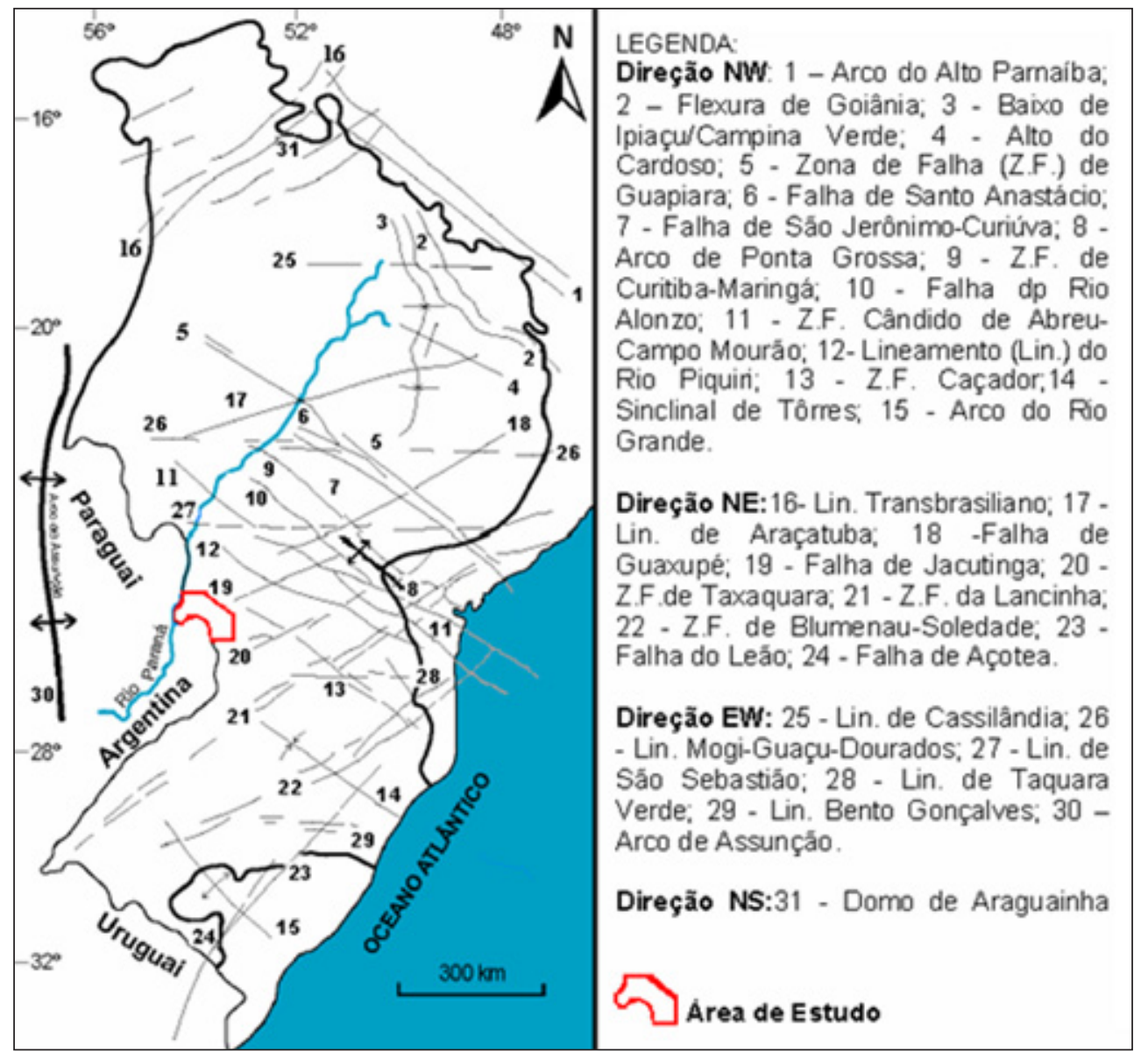

Figura 1 - Mapa do arcabouço estrutural da Bacia do Paraná no Brasil indicando a localização da área de estudo (modificado de Zalán et al. 1990). 
períodos descontínuos de sedimentação, limitados por discordâncias regionais, relacionados a variações eustáticas do nível do mar, em correspondência a eventos de subsidência no interior continental, em resposta aos esforços orogênicos paleozóicos ocorridos na borda Oeste e ao processo de abertura do oceano Atlântico Sul (Milani 1997).

O embasamento da bacia é constituído por blocos crustais soldados durante o processo colisional Brasiliano, por ocasião da consolidação do Gondwana. A importância dos trends estruturais herdados do embasamento na evolução tectono-sedimentar da Bacia do Paraná foi ressaltada por vários autores (Ferreira 1982a,b, Fúlfaro et al. 1982, Soares et al.1982, Zalán et al. 1987, Zalán et al. 1991, Soares 1991, Milani 1997, Artur 1998, Rostirolla et al .2000, Strugale et al .2007). Tais trends podem ser visualizados na figura 1 , os quais estão dispostos, principalmente, segundo as direções NW-SE, NE-SW, E-W e, secundariamente, N-S.

Na divisão em superseqüências apresentada por Milani (1997) e Milani \& Ramos (1998), na área de estudo, estão representados os litotipos pertencentes à Formação Pirambóia (Supersequência Gondwana I) e as formações Botucatu e Serra Geral (Superseqüência Gondwana III).

A Formação Pirambóia, de origem eólico-fluvial, é constituída principalmente por arenitos avermelhados, finos a médios, bem selecionados, com estratificações cruzadas de pequeno a médio porte. Quando fluvial, a granulometria varia da fração silte até areia grossa. Sucedendo este pacote ocorrem rochas pertencentes à Formação Botucatu, constituída por arenitos bimodais, médios a finos, localmente grossos e conglomeráticos, com grãos arredondados ou subarredondados, bem selecionados. Apresentam cor cinza-avermelhado e é freqüente a presença de cimento silicoso ou ferruginoso. Constituem expressivo pacote arenoso, com camadas de geometria tabular ou lenticular, espessas, que podem ser acompanhadas por grandes distâncias.

A Formação Serra Geral é constituída, essencialmente, por basaltos toleíticos a andesitos basálticos, riolitos e riodacitos subordinados, a qual recobre aproximadamente $1,2 \times 10^{6} \mathrm{~km}^{2}$ da Bacia do Paraná (Piccirillo \& Melfi 1988), correspondendo a $75 \%$ da extensão da bacia, com espessuras que variam de $350 \mathrm{~m}$ nas bordas a $1720 \mathrm{~m}$ junto ao seu depocentro. No Estado do Paraná predominam os derrames basálticos, e, com menor extensão, são registrados derrames de composição intermediária, além de ocorrências de rochas vulcânicas ácidas subordinadas. A Formação Serra Geral aflora em toda a área de estudo e é responsável pela conformação topográfica em mesetas e platôs destacados no relevo. As idades do conjunto das rochas vulcânicas, obtidas através do método Ar/Ar, posicionam o magmatismo Serra Geral no intervalo de 137 a $127 \mathrm{Ma}$ (Turner et al. 1994).

CARACTERÍSTICAS GERAIS DOS SAG E SASG O Sistema Aquífero Guarani (SAG), definido por Rocha (1997), originalmente denominado Aquífero Gigante do Mercosul (Araújo et al. 1995), é constituí- do predominantemente por arenitos que se depositaram na Bacia do Paraná ao longo do Mesozóico. O SAG é composto pelas formações Pirambóia e Rosário do Sul no Brasil, Missiones no Paraguai e Buena Vista na Argentina e no Uruguai, além dos arenitos eólicos das Formações Botucatu no Brasil, Missiones no Paraguai e Tacuarembó na Argentina e no Uruguai. No Estado do Paraná o SAG ocupa uma área aproximada de 131.300 $\mathrm{km}^{2}$ (Araújo et al. 1999), cerca de $15 \%$ da porção brasileira do aqüífero.

$\mathrm{O}$ volume de água estimado do SAG varia de 37 a 50 mil km³. Esses volumes distintos são decorrentes dos diferentes parâmetros dimensionais (espessura média e área) e coeficientes de porosidade efetiva, adotados pelos autores. A composição química das águas é muito variável, principalmente nas zonas confinadas, seja por efeitos de variações faciológicas, seja por influência de misturas induzidas por fraturas. Ainda quanto ao quimismo, segundo Sracek \& Hirata (2002), existem evoluções de águas bicarbonatadas cálcicas nas áreas de afloramento e de baixo confinamento, para águas bicarbonatadas sódicas, derivadas do incremento das concentrações de cloretos e sulfatos em profundidade, nas zonas de alto confinamento. Esta mudança na composição química da água se dá através da diminuição do cálcio, por intercâmbio com o sódio, originada pela dissolução dos carbonatos, fazendo com que as águas evoluam para bicarbonatadas sódicas. Parte do sódio envolvido nas reações é oriundo provavelmente do SAG e a adição de cloretos e sulfatos parece se relacionar com a dissolução de evaporitos, como halita $(\mathrm{NaCl})$ e mirabilita $\left(\mathrm{Na}_{2} \mathrm{SO}_{4} \cdot 10 \mathrm{H}_{2} \mathrm{O}\right)$, ou gibsita e difusão de produtos de dissolução da Formação Pirambóia.

O Sistema Aquífero Serra Geral (SASG), formado entre o Jurássico Superior e o Cretáceo Inferior, predominantemente do tipo fraturado, envolve uma área aproximada de $1,5 \times 10^{6} \mathrm{~km}^{2}$ e constitui-se na capa protetora do SAG, sendo composto por rochas ígneas vulcânicas representadas por basaltos toleíticos e andesitos, ocorrendo quantidades subordinadas de riolitos e riodalitos (Milani, 1997). Esse aqüífero, geologicamente relacionado à Formação Serra Geral no Brasil, recebe as denominações Alto Paraná no Paraguai, Arepey no Uruguai (Rebouças et al. 2002) e Curuzú, na Argentina (Kittl 2000).

No Estado do Paraná, o SASG aflora no Terceiro Planalto Paranaense, correspondendo a aproximadamente $1,1 \times 10^{6} \mathrm{~km}^{2}$. O mergulho regional dessas rochas ocorre na direção Leste-Sudoeste, em cotas próximas de $1,1 \times 10^{3} \mathrm{~m}$ na sua borda Leste, até um mínimo de 49 $\mathrm{m}$ na foz do rio Iguaçu. A espessura máxima dessa formação é de $1,4 \times 10^{3} \mathrm{~m}$ na região do rio Piquiri (Araújo et al. 1995).

O SASG, fissural, não possui porosidade e permeabilidade primária. Assim sendo, a água necessita de descontinuidades físicas nas rochas para que sejam transportadas e armazenadas. Estas descontinuidades denotam ao sistema características heterogêneas e anisotrópicas (Rebouças 1978), do que decorre condutividade hidráulica muito variável, complexa e de difícil 
avaliação (Fraga 1986). Estudos realizados nesse contexto (Bittencourt 1978, Fraga 1986, Rosa Filho et al. 1987, Celligoi 1994, Bittencourt et al. 2003), definiram a composição química das águas do SASG como bicarbonatada cálcica, decorrente da ação intempérica dos basaltos típicos.

A recarga principal do SASG ocorre através da pluviometria, principalmente em áreas com desenvolvido manto de alteração, topografia pouco acidentada e considerável cobertura vegetal (mata nativa). Em termos de potabilidade, as águas dos basaltos relevam uma forte tendência ácida ( $\mathrm{pH}$ entre 5,5 e 6,5) e mineralização total inferior a $300 \mathrm{mg} / \mathrm{L}$. O SASG é considerado um importante sistema de abastecimento, suprindo mais de $70 \%$ dos núcleos urbanos do Estado do Paraná com água de ótima qualidade.

MATERIAL E MÉTODOS A determinação do arcabouço magnético-estrutural da área de estudo foi baseado em dois níveis de investigação. Para a geração do arcabouço estrutural de superfície foram usados os lineamentos interpretados com base no Modelo Digital de Elevação (MDE - células de $90 \mathrm{~m}$ provenientes do sensor SRTM - Shuttle Radar Topography Mission - NASA) e na análise morfoestrutural da rede de drenagem. $\mathrm{O}$ arcabouço geofísico-estrutural de subsuperfície foi fundamentado no processamento e na interpretação dos dados aeromagnéticos provenientes do Projeto Aerogeofísico Borda Oeste da Bacia do Paraná (Bloco Leste/Sul), executados para a Petróleo Brasileiro S.A. (Petrobras), entre 11/1989 e 01/1990. O levantamento foi executado segundo linhas espaçadas de $3.000 \mathrm{~m}$ na direção N-S, a uma altura barométrica de $1.000 \mathrm{~m}$, com intervalo de amostragem de $100 \mathrm{~m}$. Os dados aeromagnéticos foram fornecidos pela Companhia de Pesquisa de Recursos Minerais (CPRM) ao Laboratório de Pesquisas em Geofísica Aplicada da Universidade Federal do Paraná (LPGA/UFPR), já tratados e corrigidos dos erros de posicionamento, nivelamento das linhas, deriva de vôo e remoção do campo magnético principal da Terra (International Geomagnetic Reference Field - IGRF), para o período do levantamento. Por comparação, em ambiente de Sistema de Informação Geográfica (SIG), tais resultados foram harmonizados em um arcabouço magnético-estrutural regional.

A comparação de tal arcabouço com os dados hidrogeológicos (181 poços) e hidroquímicos (100 poços com erro de balanço iônico inferior a $10 \%$ ), completados na Formação Serra Geral, cedidos pela Superintendência de Desenvolvimento de Recursos Hídricos e Saneamento Ambiental (Suderhsa) e Companhia de Saneamento do Paraná (Sanepar), permitiram avaliar a influência estrutural no condicionamento das variáveis hidrogeológicas e hidroquímicas, interpretar as supostas zonas de mesclagem de águas, assim como delinear a compartimentação dos dois sistemas aqüíferos. Visando fornecer subsídios a classificação química das águas na área de estudo, foram contempladas análises químicas de 54 amostras de rochas basálticas cedidas pela Minerais do Paraná S/A (Mineropar), nas quais foram determinados nove elementos maiores $\left(\mathrm{SiO}_{2}, \mathrm{TiO}_{2}, \mathrm{Al}_{2} \mathrm{O}_{3}, \mathrm{Fe}_{2} \mathrm{O}_{3}, \mathrm{MgO}, \mathrm{CaO}, \mathrm{K}_{2} \mathrm{O}, \mathrm{Na}_{2} \mathrm{O}\right.$ e $\mathrm{P}_{2} \mathrm{O}_{5}$ ). Isso possibilitou classificar geoquimicamente às rochas da região e verificar as oscilações dos teores de elementos alcalinos e alcalino-terrosos nas águas do SASG, derivadas dos basaltos.
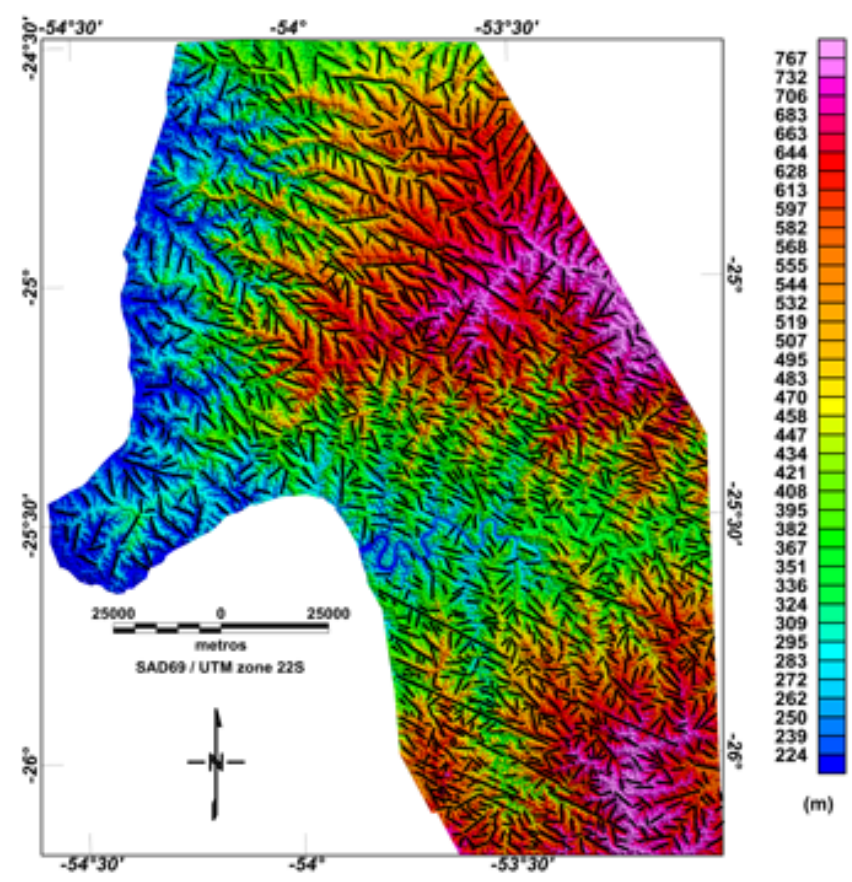

Figura 2 - MDE e os principais lineamentos.

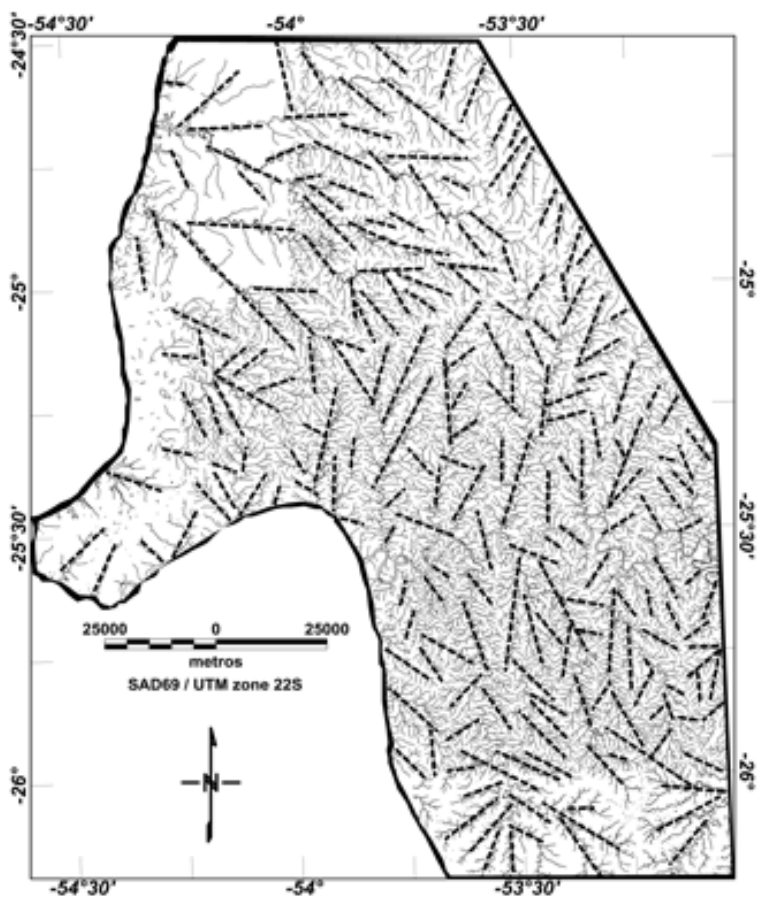

Figura 3 - Rede de drenagem e os principais lineamentos. 


\section{RESULTADOS E DISCUSSÃO}

Arcabouço de Superfície A caracterização do arcabouço de superfície foi baseada na interpretação dos lineamentos extraídos do MDE (Fig. 2) e da rede de drenagem (Fig. 3), os quais podem ser visualizados em conjunto na figura 4. Como se pode observar na figura 4, o padrão de drenagem (linhas tracejadas) está condicionado pelos lineamentos negativos (linhas contínuas) extraídos do MDE, em adição às estruturas de Soares et al. (1982). Esta última figura exibe tendências segundo NW-SE, NE-SW, NNE-SSW e N-S, as quais são coerentes com as direções definidas por vários autores (e.g. Ferreira 1982 a,b, Fúlfato et al. 1982, Soares et al.1982, Zalán et al.1991, Artur 1998).

Arcabouço de Subsuperfície Inicialmente, os dados aeromagnéticos foram interpolados pelo método da curvatura mínima (Briggs 1974), por meio de malhas regulares de $750 \times 750 \mathrm{~m}$ (1/4 do espaçamento nominal das linhas de vôo). A presença de artefatos ao longo das linhas de vôo, decorrentes de erros de nivelamento, exigiu procedimentos de micronivelamento (Minty 1991). A partir da malha micronivelada do campo magnético residual foram aplicados, dentre outros, os seguintes filtros: amplitude do gradiente horizontal total (Cordell \& Grauch 1985), amplitude do sinal analítico (Nabighian 1972); inclinação do sinal analítico (Miller \& Singh 1994), gradiente horizontal total da inclinação do sinal analítico (Verduzco et al. 2004), Theta map (Winjs et al. 2005) e inclinação do sinal analítico do gradiente horizontal total (Ferreira \& Abram 2005). Tais filtros foram testados na malha original $(1000 \mathrm{~m})$ e nas continuadas para cima $(2000,3000,4000$ e $5000 \mathrm{~m})$, do que resultou na geração de mais de 50 mapas. A comparação deles, para um mesmo tema de processamento, mostrou que os melhores produtos para a interpretação magnética foram os derivados da malha continuada para $5000 \mathrm{~m}$ (Fig. 5). Assim, foram selecionados para apresentação os mapas decorrentes do processamento do último grid, os quais se mostraram melhores para delinear o arcabouço de subsuperfície.

As figuras 6, 7, 8, 9 e 10 mostram, respectivamente, os mapas da amplitude do gradiente horizontal total, da amplitude do sinal analítico, da inclinação do sinal analítico, Theta map e da inclinação do sinal analítico do gradiente horizontal total.

Com base nas figuras 5 a 10, foi concebido o mapa do arcabouço de subsuperfície (Fig. 11), o qual exibe as principais estruturas e zonas magnéticas anômalas. Na figura 11, os lineamentos de direção NE-SW são preferenciais na porção meridional da área, enquanto no trato setentrional dominam direções NW-SE. As feições de direção E-W são subordinadas e ocorrem, preferencialmente, na região central da área de estudo. A ausência de tendências geofísicas na direção N-S deve-se ao paralelismo com as linhas de vôo e ao micronivelamento executado naquela direção.

No arcabouço geofísico de subsuperfície (Fig. 11) também são assinaladas anomalias de configurações elípticas, que se orientam segundo as direções NE-SW e E-W, portanto controladas estruturalmente, podendo refletir a existência de rochas máficas/ultramáficas em profundidade. Dentre estas, a que merece atenção especial é aquela disposta segundo NE-SW, situada no extremo Oeste da área (Figs. 6 e 7), a qual pode se relacionar ao Grabén de Foz do Iguaçu/Araçatuba, como denominado por Marques et al. (inédito), feição que integra o Rifte Central da Bacia do Paraná.

Arcabouço Integrado No arcabouço integrado (Fig. 12), se verificou que todas as tendências, principalmente dispostas segundo NW-SE, NE-SW, NNE-SSE e E-W, refletem as respectivas direções definidas por Soares et al. (1982). Destacam-se claramente conjuntos de lineamentos segundo NW-SE, talvez refletindo cerrados enxames de diques máficos, os quais, certamente, influenciam a circulação das águas subterrâneas. Tais lineamentos, juntamente com outras estruturas dispostas principalmente segundo a direção NE-SW, são de fundamental importância na compartimentação dos SASG e SAG.

Nota-se também que a anomalia magnética localizada no extremo Oeste da área de estudo exibe direção coincidente à PT-4 de Soares et al. (1982), e que a anomalia do quadrante Sudeste, de direção E-W, se aproxima do curso do rio Iguaçu. Um dos aspectos mais importantes da interpretação integrada foi à constatação da existência de uma alta densidade de lineamentos de superfície compatíveis às tendências magnéticas mapeadas.

Hidrogeologia e Hidroquímica Este estudo foi desenvolvido com base em dados hidrogeológicos e hidroquímicos cedidos pela Suderhsa e Sanepar, oriundos de poços tubulares completados na Formação Serra Geral. Considerou-se importante nesta abordagem o exame das seguintes variáveis: profundidade de perfuração, potenciometria, vazão de explotação, capacidade específica, potencial hidrogeniônico $(\mathrm{pH})$, sólidos totais dissolvidos (STD), além dos cátions $\left(\mathrm{Na}^{+} ; \mathrm{K}^{+} ; \mathrm{Ca}^{2+}\right.$ ; $\left.\mathrm{Mg}^{2+}\right)$ e dos ânions $\left(\mathrm{HCO}_{3}^{-} ; \mathrm{CO}_{3}{ }^{2-} ; \mathrm{Cl}^{-} ; \mathrm{SO}_{4}{ }^{2-}\right)$. As tabelas 1 e 2 mostram as estatísticas destas variáveis.

Os dados hidrogeológicos e hidroquímicos foram interpolados e contornados através de células quadradas de $5000 \times 5000 \mathrm{~m}$. Em seguida foram gerados mapas de contorno das variáveis citadas, os quais foram confrontados ao arcabouço magnético-estrutural simplificado (lineamentos geofísicos e estruturas de Soares et al. 1982), com o objetivo de averiguar suas eventuais relações.

Os mapas de vazão e capacidade específica (Figs. 13 e 14, 181 poços) mostram que às porções Norte e Noroeste da área de estudo apresentam valores médios superiores aos da porção Sul, sugerindo que o SASG é heterogêneo e anisotrópico (Rebouças \& Fraga 1988). Também se nota que as áreas com altas produtividades estão aparentemente confinadas em compartimentos balizados pelas estruturas de Soares et al. (1982), as quais, por sua vez, se vinculam às feições magnéticas subparalelas.

$\mathrm{O}$ mapa do potencial hidrogeniônico ( $\mathrm{pH}$, Fig. 


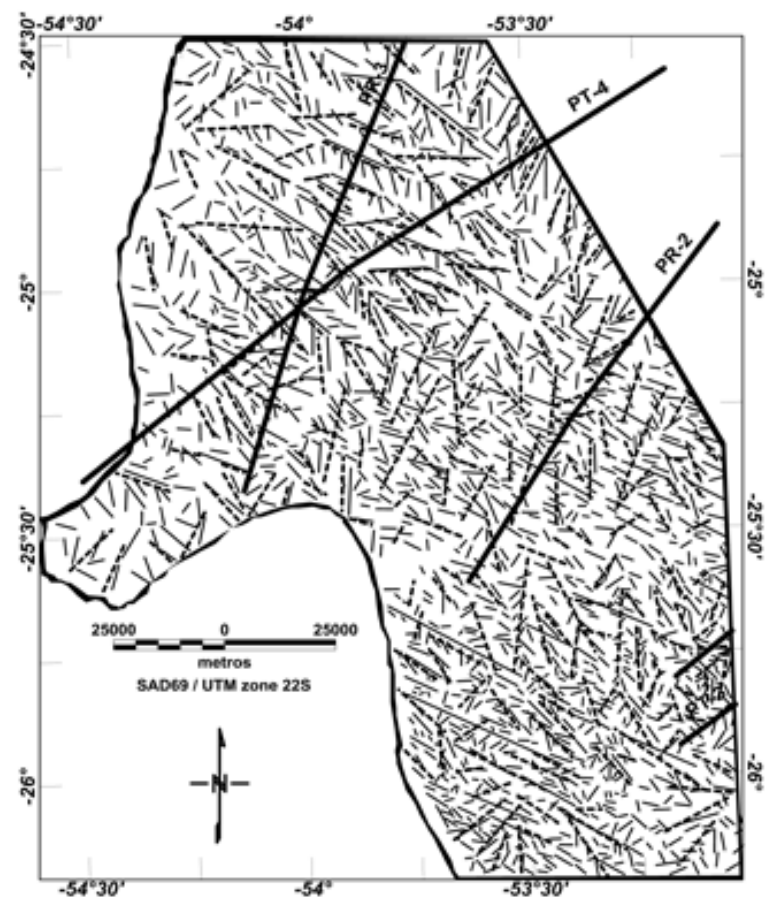

Figura 4 - Mapa do arcabouço de superfície indicando as estruturas de Soares et al. (1982).
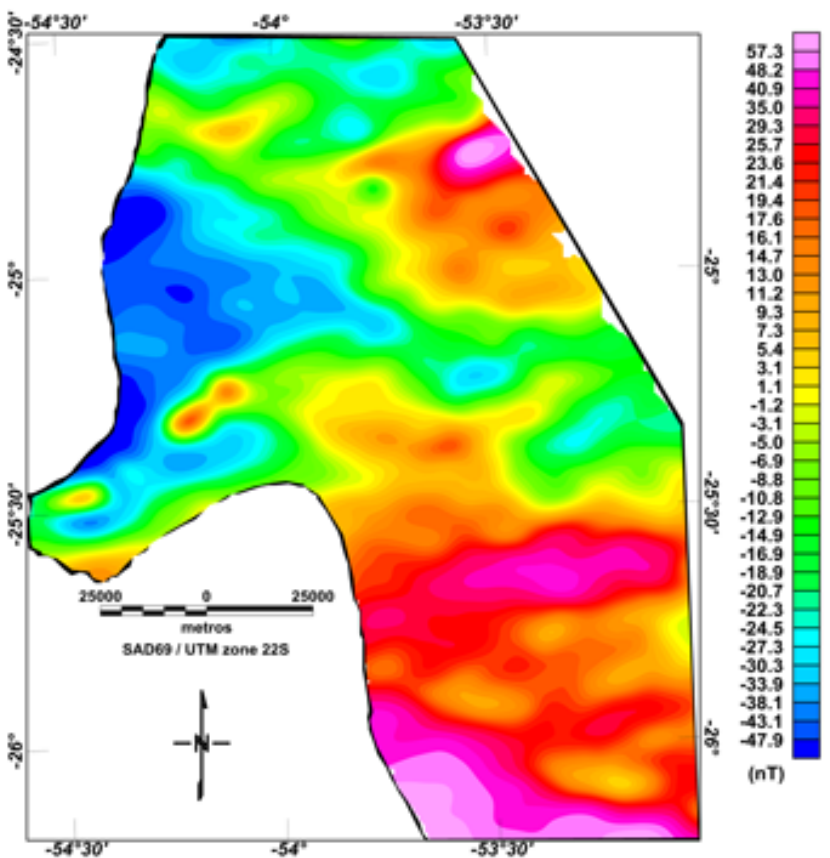

Figura 5 - Mapa do campo magnético residual micronivelado $(5.000 \mathrm{~m})$.

15, 181 poços), mostra que os valores alcalinos, em vermelho/magenta, dominam a Norte de PT-4 e a Sul de PR-2, sendo que a região entre estas feições estruturais denotam valores com tendência a acidez. Os valores alcalinos de $\mathrm{pH}(>8,0)$ podem ser atribuídos às águas subterrâneas com contribuição do $\mathrm{SAG}$, pois o

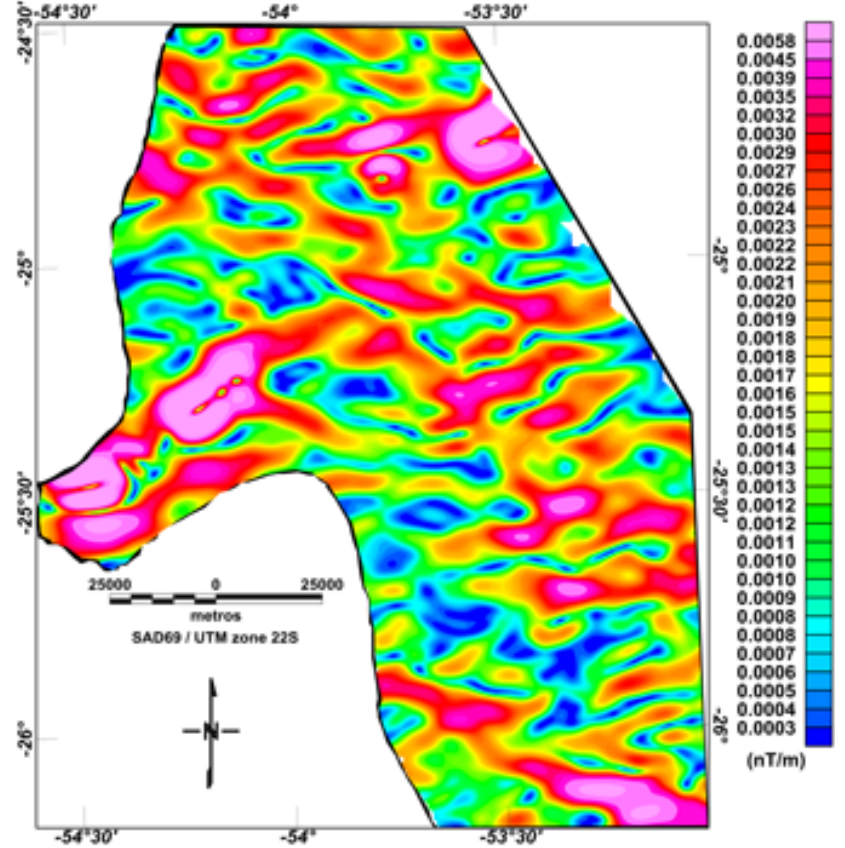

Figura 6 - Mapa da amplitude do gradiente horizontal total $(5.000 \mathrm{~m})$.

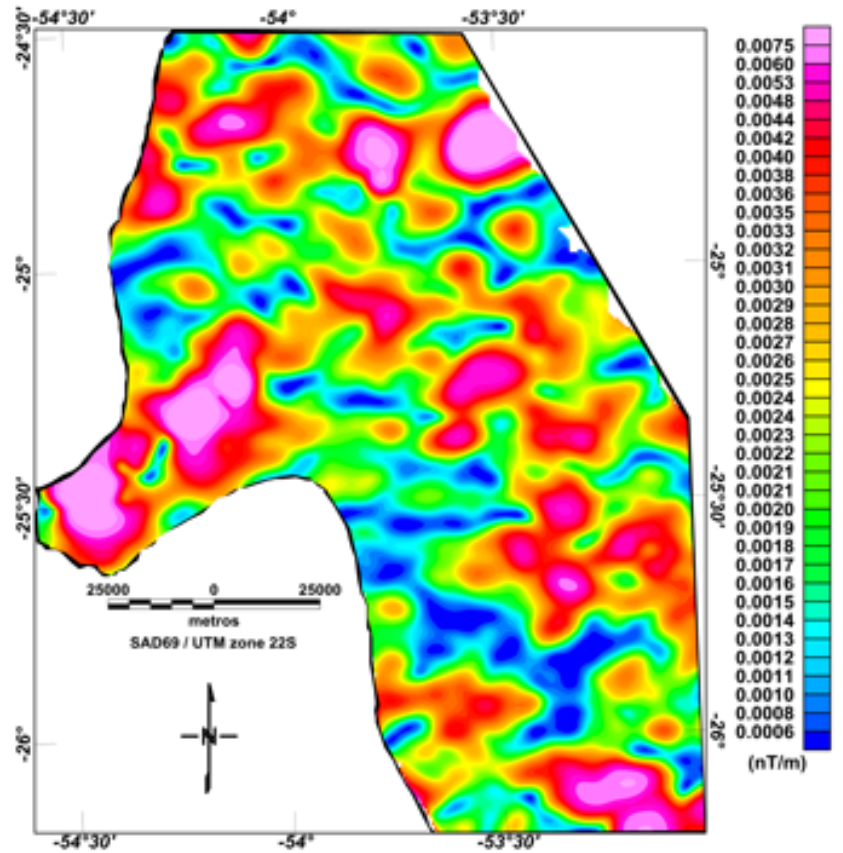

Figura 7 - Mapa da amplitude do sinal analitico (5.000m).

aumento da alcalinidade implica em desequilíbrio do $\mathrm{CO}_{3}{ }^{2-}$, ocasionando depleção de $\mathrm{Ca}^{2+}$, do que decorre um incremento do sódio.

O mapa de contorno dos sólidos totais dissolvidos (STD, Fig. 16, 181 poços) exibe tratos de maior concentração na metade meridional da área de estudo, 


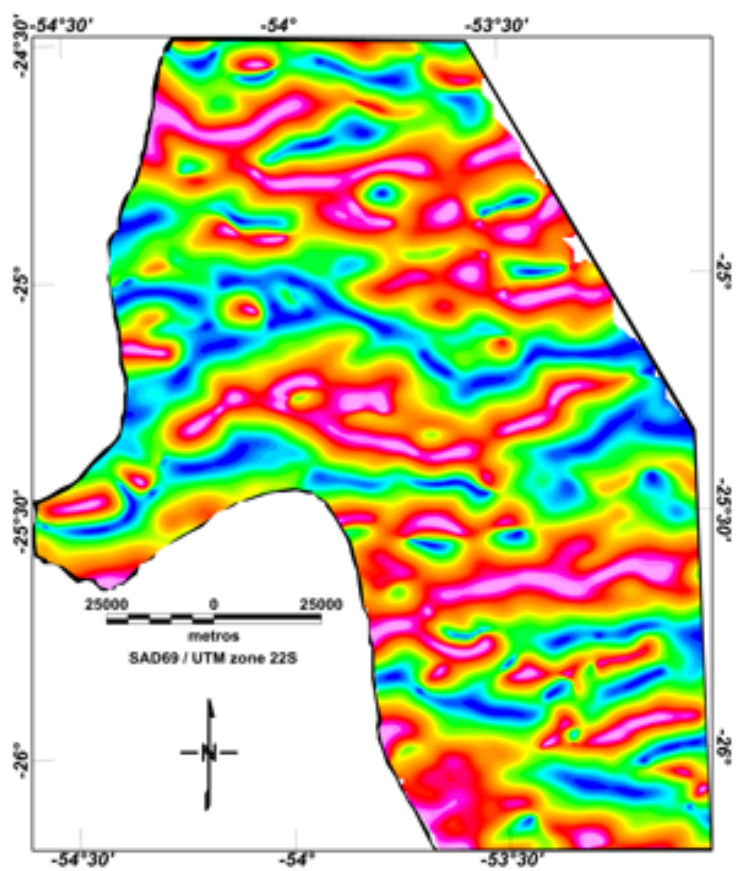

Figura 8 - Mapa da inclinação do sinal analítico (5.000m).

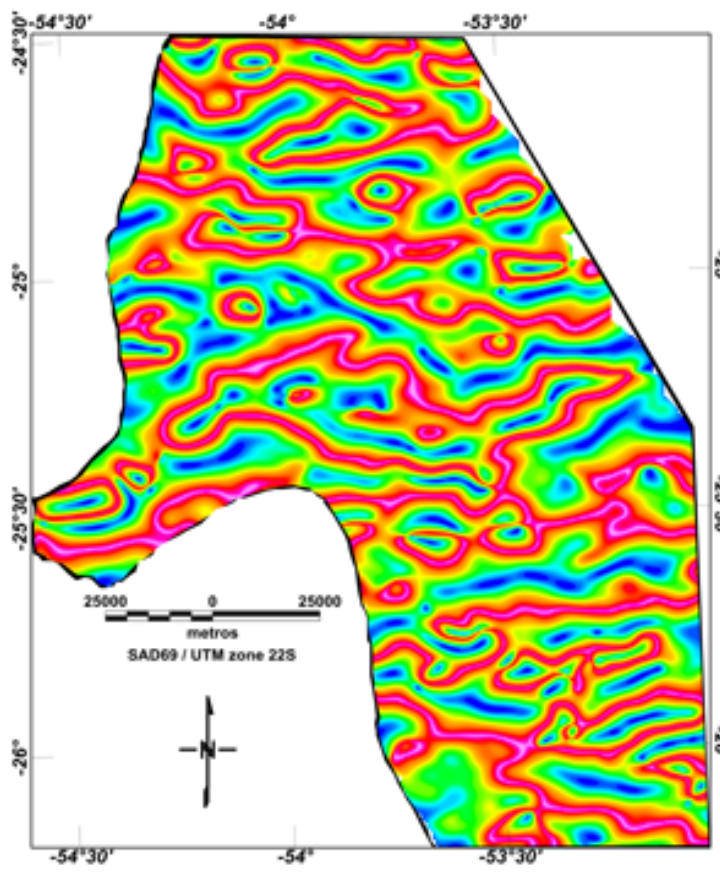

Figura 9 - Theta map $(5.000 \mathrm{~m})$.

parte dos quais parece se conformar às estruturas magnéticas vizinhas a PT-3, PR-2 e PT-4. A proximidade de maiores concentrações de STD e pH das estruturas, indica que a circulação/renovação das águas são restritas (maior tempo de residência) e/ou decorrente de contribuição do SAG.

A análise conjunta dos quatro últimos mapas

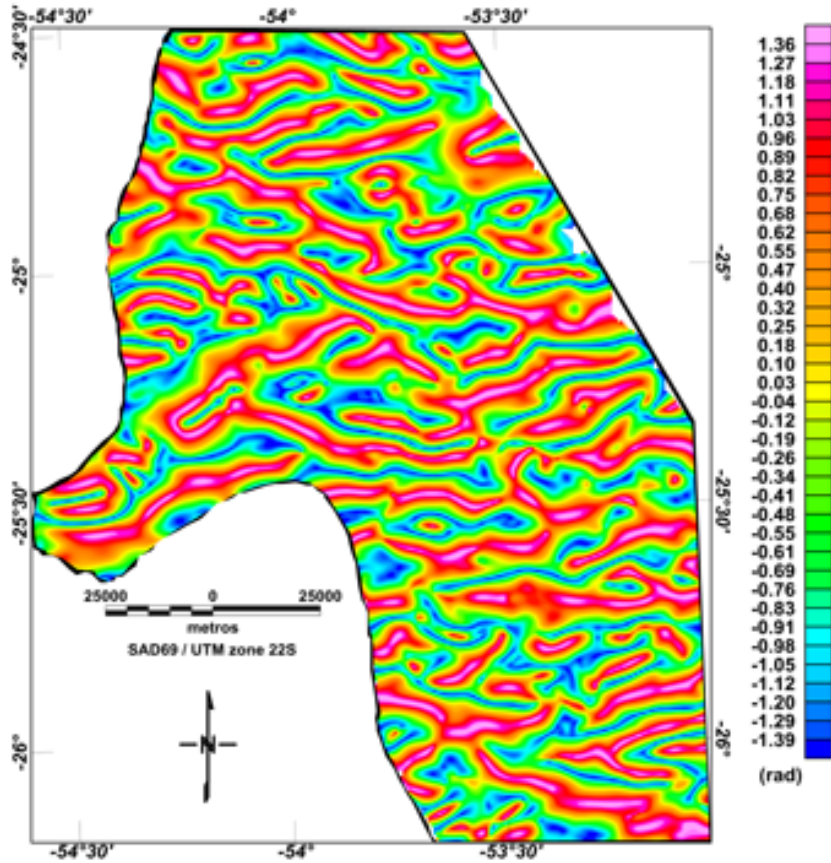

Figura 10 - Mapa da inclinação do sinal analítico do gradiente horizontal total $(5.000 \mathrm{~m})$.

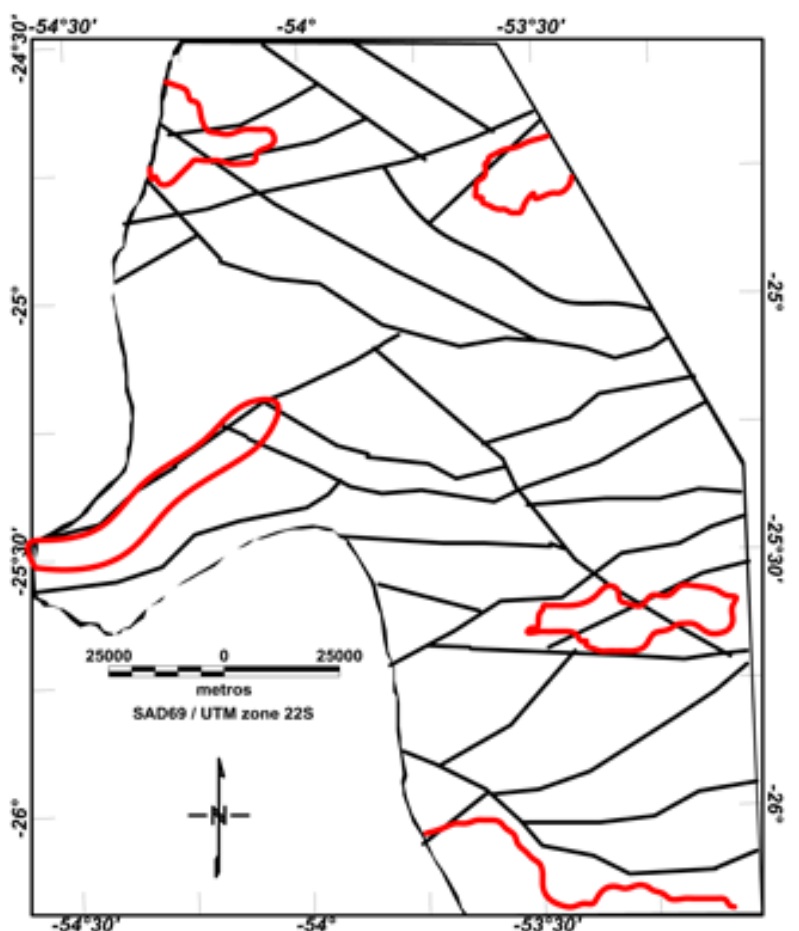

Figura 11 - Mapa do arcabouço de subsuperficie indicando as principais zonas anômalas (em vermelho).

(Figs. 13, 14, 15 e 16), revela que as áreas de menor produtividade (Figs. 13 e 14) coincidem com aquelas de valores elevados de $\mathrm{pH}$ e STD (Figs. 15 e 16). Essa coincidência pode estar relacionada à presença de fra- 


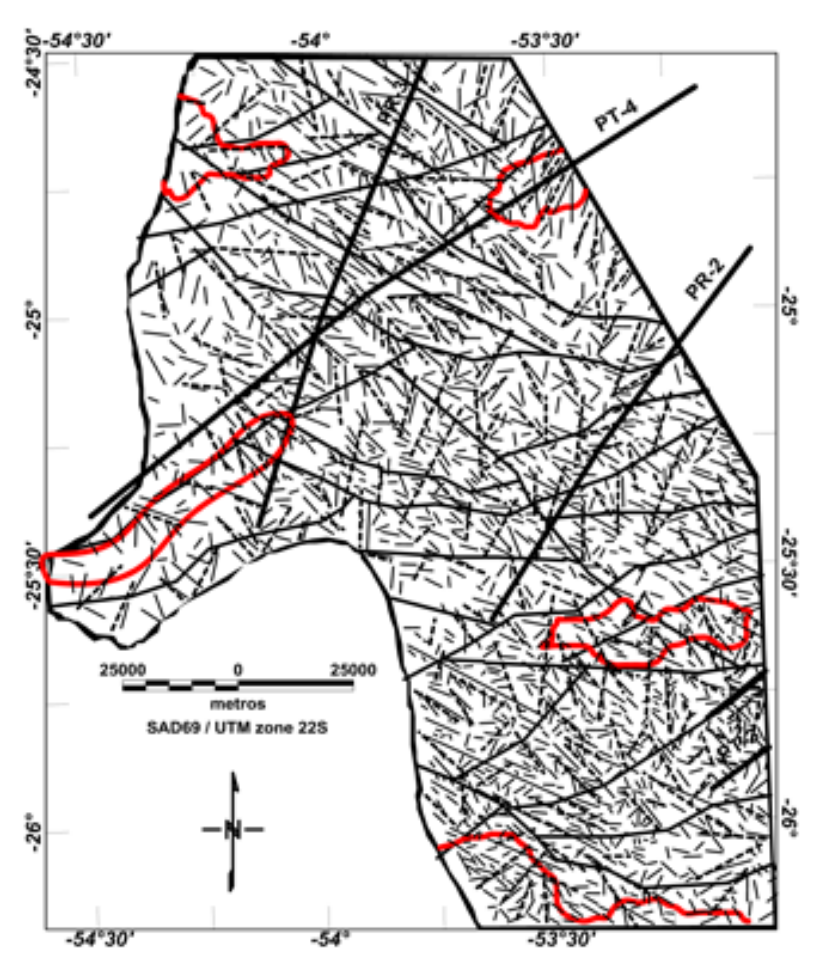

Figura 12 - Mapa do arcabouço estrutural-magnético integrado. turas ou falhas preenchidas por diques de diabásio, os quais, neste caso, atuariam como barreiras ao fluxo das águas. Portanto, é possível que nestes tratos o tempo de residência das águas subterrâneas seja maior, os quais, aliado a profundidades, temperaturas e pressões elevadas, facilitariam o incremento da concentração salina das águas. Por outro lado, a estruturação das áreas com elevados índices de $\mathrm{pH}$ e STD pode favorecer a conectividade dos SASG e SAG, como já sugerido por Ferreira et. al (2005) e Portela Filho et. al (2005).

$\mathrm{O}$ estudo hidroquímico teve por finalidade identificar e quantificar os principais constituintes das águas subterrâneas. Os processos que atuam na evolução de sua qualidade podem ser intrínsecos ou extrínsecos ao aqüífero. Assim, a composição hidroquímica pode sofrer alterações na medida em que percolam diferentes aquíferos (SAG/SASG), além da influência de outros fatores como clima, composição química da água de recarga, tempo de residência e contaminação provocada pelo homem.

Foram selecionados para a pesquisa apenas os dados hidroquímicos que apresentaram erros de balanço iônico inferiores a 10\%. Portanto, de um universo de 181 registros, apenas 100 análises químicas foram consideradas adequadas para o estudo. A classificação das águas do SASG foi determinada através do diagrama de Piper (Fig. 17), no qual foram plotados os dados em $\mathrm{mg} / \mathrm{L}$ dos macroconstituintes iônicos.

Tabela 1 - Estatística básica dos parâmetros hidrogeológicos da área de estudo.

\begin{tabular}{l|c|c|c|c|c|c}
\hline Estatísticas & $\begin{array}{c}\text { Profundidade } \\
\mathrm{m}\end{array}$ & $\begin{array}{c}\text { Nível } \\
\text { potenciométrico } \\
\mathrm{m}\end{array}$ & $\begin{array}{c}\text { Vazão } \\
\mathrm{m}^{3} / \mathrm{h}\end{array}$ & $\begin{array}{c}\text { Cap. Específica } \\
{\left[\left(\mathrm{m}^{3} / \mathrm{h}\right) / \mathrm{m}\right]}\end{array}$ & $\mathrm{pH}$ & $\begin{array}{c}\mathrm{STD} \\
\mathrm{mg} / \mathrm{L}\end{array}$ \\
\hline Máximo & 990,00 & 736,55 & 250,00 & 83,33 & 10,09 & 1076,00 \\
\hline Mínimo & 47,00 & 162,56 & 1,10 & 0,02 & 5,95 & 30,00 \\
\hline Média & 155,89 & 402,02 & 25,75 & 3,99 & 8,01 & 127,51 \\
\hline Desvio Padrão & 90,24 & 145,67 & 37,30 & 9,60 & 0,92 & 101,24 \\
\hline Mediana & 130,00 & 386,00 & 11,00 & 1,01 & 7,81 & 118,00 \\
\hline $\mathrm{N}^{\circ}$ de dados & 180 & 181 & 181 & 181 & 181 & 181 \\
\hline
\end{tabular}

Tabela 2 - Estatística básica dos parâmetros hidroquímicos (cátions e ânions em $\mathrm{mg} / \mathrm{L}$ ) da área de estudo.

\begin{tabular}{l|c|c|c|c|c|c|c|c}
\hline Estatística & $\mathrm{HCO}_{3}^{-}$ & $\mathrm{CO}_{3}{ }^{--}$ & $\mathrm{Cl}^{-}$ & $\mathrm{SO}_{4}{ }^{-2}$ & $\mathrm{Ca}^{2+}$ & $\mathrm{Mg}^{+2}$ & $\mathrm{Na}^{+}$ & $\mathrm{K}^{+}$ \\
\hline Máximo & 221,82 & 62,40 & 49,70 & 580,00 & 45,46 & 28,10 & 320,00 & 5,10 \\
\hline Mínimo & 4,55 & 0,00 & 0,03 & 0,50 & 0,61 & 0,02 & 0,20 & 0,01 \\
\hline Média & 91,49 & 9,23 & 3,14 & 7,71 & 14,45 & 3,99 & 23,58 & 0,66 \\
\hline Desvio Padrão & 36,55 & 17,50 & 5,80 & 58,61 & 8,84 & 3,87 & 36,72 & 0,65 \\
\hline Mediana & 85,63 & 0 & 1,13 & 0,5 & 14,80 & 3,88 & 11,20 & 0,55 \\
\hline $\mathrm{N}^{\circ}$ de dados & 100 & 100 & 100 & 99 & 100 & 100 & 100 & 100 \\
\hline
\end{tabular}




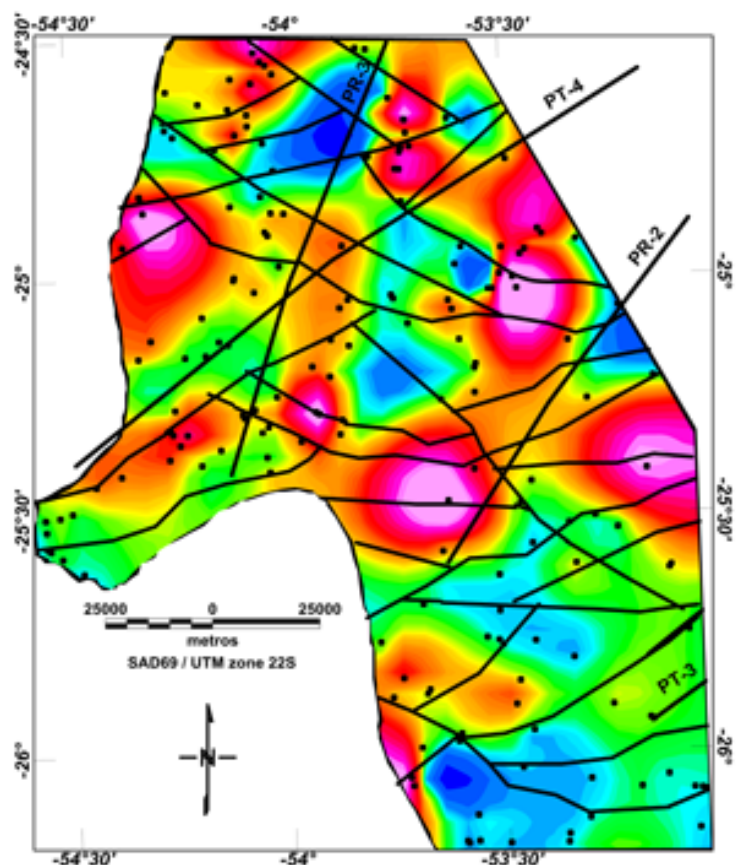

Figura 13 - Mapa de vazão de explotação.

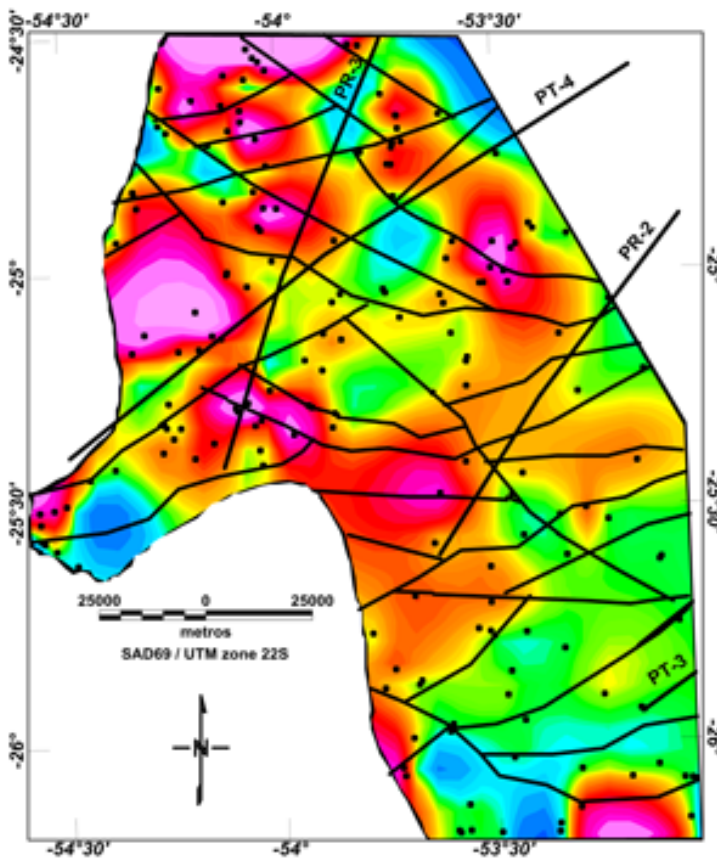

Figura 14 - Mapa da capacidade especifica.

Perfazendo $47 \%$ das amostras analisadas, as águas bicarbonatadas cálcicas (concentração média de cálcio $19,49 \mathrm{mg} / \mathrm{L}$ ), representando $60,11 \%$ do total de cátions majoritários, estão diretamente relacionadas ao arcabouço químico-mineralógico do aqüífero, pois reflete a remoção do cálcio dos plagioclásios e minerais ferromagnesianos dos basaltos. A solubilidade do $\mathrm{Ca}^{2+}$ em águas naturais está vinculada à presença de espécies carbônicas dissolvidas como $\mathrm{H}_{2} \mathrm{CO}_{3}, \mathrm{HCO}_{3}^{-}$e $\mathrm{CO}_{3}$

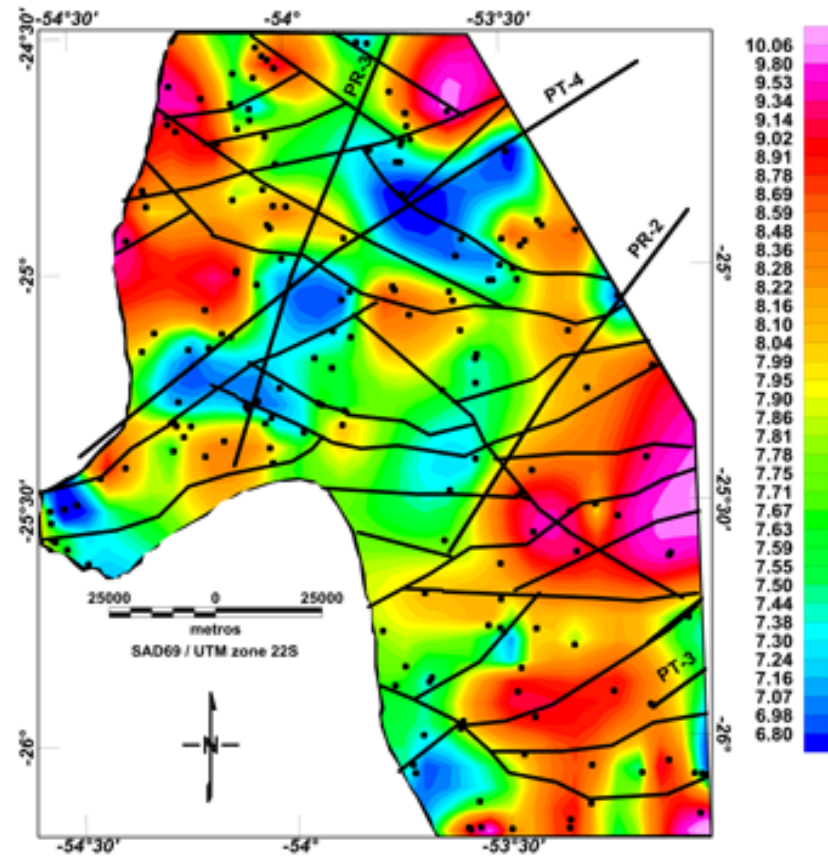

Figura 15 - Mapa do potencial hidrogeniônico (pH).

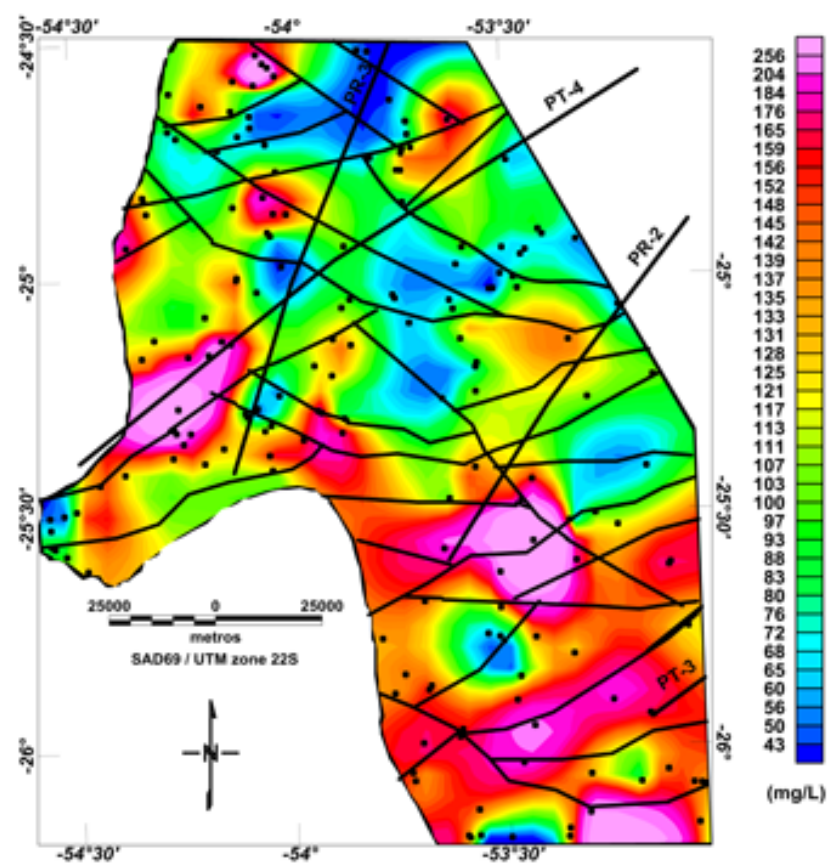

Figura 16 - Mapa de sólidos totais dissolvidos (STD).

2-. Com relação aos demais cátions, o sódio responde por $22,37 \%$, seguido do magnésio $(15,33 \%)$ e do potássio $(2,19 \%)$, cujos teores médios respectivos são 7,25 $\mathrm{mg} / \mathrm{L}, 4,97 \mathrm{mg} / \mathrm{L}$ e $0,71 \mathrm{mg} / \mathrm{L}$.

A profundidade média de entrada de água nos poços é $58,04 \mathrm{~m}$ e suas elevações variam de 226,00 a $743,01 \mathrm{~m}$. Os valores de $\mathrm{pH}$ oscilam de 6,82 a 8,65, intervalo de predomínio do íon bicarbonato, gerado diretamente por decomposição do ácido carbônico, ou 


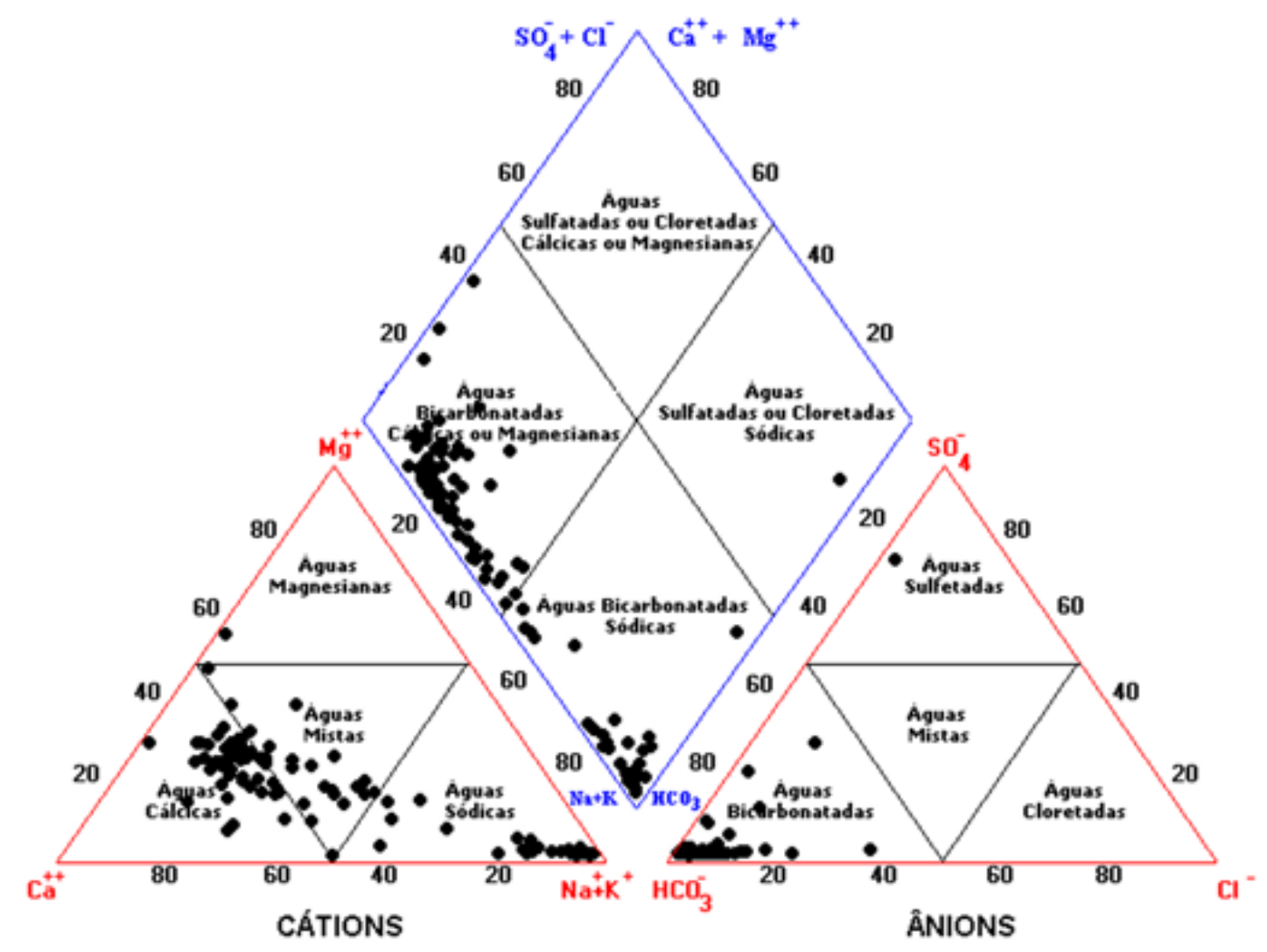

Figura 17 - Diagrama de Piper mostrando a composição química das águas do SASG.

como produto da hidrólise dos silicatos dos basaltos. O teor médio do íon bicarbonato é $92,09 \mathrm{mg} / \mathrm{L}$, com valores entre 20,53 e $221,82 \mathrm{mg} / \mathrm{L}$, representando $96,26 \%$ do total de ânions majoritários presente. A concentração média de sólidos totais dissolvidos é $125,11 \mathrm{mg} / \mathrm{L}$. São águas que apresentam pouco tempo de residência, com recarga relacionada às precipitações pluviométricas através do manto de intemperismo. Para Bittencourt et al. (2003), esta fácies é a que melhor representa as características do SASG e sua distribuição é homogênea em toda a área de estudo.

As águas bicarbonatadas sódicas (30\% do total) apresentam uma forte tendência alcalina, visto que o $\mathrm{pH}$ de 93,30\% das amostras é superior a 8,00 (máximo de 10,09). Nestas águas o teor médio de STD é de $148,85 \mathrm{mg} / \mathrm{L}$. Para tais amostras, a relação $\mathrm{Na}^{+} / \mathrm{Ca}^{2+}$ é superior a um, significando que o sódio é o íon predominante $(88,45 \%$ do total de cátions majoritários). As características desta fácies não correspondem a um aqüífero suportado por basaltos típicos, e por isto podem ser consideradas como resultantes de contribuições de aqüíferos sotopostos. A profundidade média de entrada de água é 100,82 m e suas elevações oscilam de 229,00 a $680,88 \mathrm{~m}$.

Em águas superficiais o sódio é freqüentemente atribuído a contaminações antrópicas, o que pode ocorrer em alguns poços pouco profundos, cujo tempo de residência das águas é menor em face de sua constante renovação. Na maioria dos casos o ambiente alcalino eleva a relação $\mathrm{Na}^{+} / \mathrm{Ca}^{2+}$, como decorrência da insolubilização do cálcio e também do magnésio. $\mathrm{O}$ ambiente do SAG em condições de confinamento reflete tal contexto. Portanto, águas cálcicas e cálcio-magnesianas, típicas do SASG, podem tender para águas sódicas mediante taxas variadas de mistura com águas de aquíferos subjacentes (e.g. Bittencourt 1978, Rosa Filho et al. 1987, Bittencourt et al. 2003).

As águas mistas ( $21 \%$ do total) englobam as fácies bicarbonatadas cálcio-magnesianas à bicarbonatadas cálcio-sódicas. Em relação ao total de cátions majoritários, o cálcio representa $44,26 \%$, seguido do sódio $(38,30 \%)$, do magnésio $(15,24 \%)$ e do potássio $(2,20$ $\%$ ). A relação $\mathrm{Na}^{+} / \mathrm{Ca}^{2+}$ é superior a um em $47,61 \%$ das amostras, enquanto a razão $\mathrm{Mg}^{2+} / \mathrm{Ca}^{2+}$ é inferior a 0,65 em todas as amostras. Composições tendendo para o vértice sódico, como já mencionado, sugerem contribuições de fontes subbasálticas, enquanto teores maiores de magnésio, segundo Bittencourt et. al (2003) podem perfeitamente se relacionar aos basaltos da Formação Serra Geral.

O bicarbonato é o íon predominante, responsável por $93,64 \%$ do total de ânions majoritários analisados, com concentração média de 100,94 mg/L. Estas águas são levemente alcalinas, pois os valores do $\mathrm{pH}$ oscilam de 6,84 a 9,02 , com $57,14 \%$ dos valores acima de 8,00 . O teor médio de sólidos totais dissolvidos foi de 128,14 $\mathrm{mg} / \mathrm{L}$, podendo assumir valores próximos a $200,00 \mathrm{mg} / \mathrm{L}$. A profundidade média de entrada de água é de $57,21 \mathrm{~m}$ e 


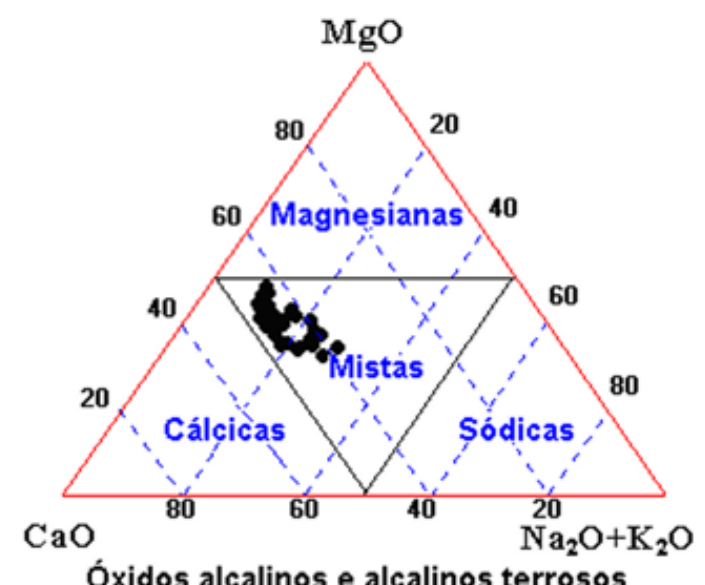

Figura 18 - Diagrama triangular da composição química $\left(\mathrm{MgO}, \mathrm{CaO}, \mathrm{K}_{2} \mathrm{O}+\mathrm{Na}_{2} \mathrm{O}\right)$ de basaltos da Formação Serra Geral na área de estudo.

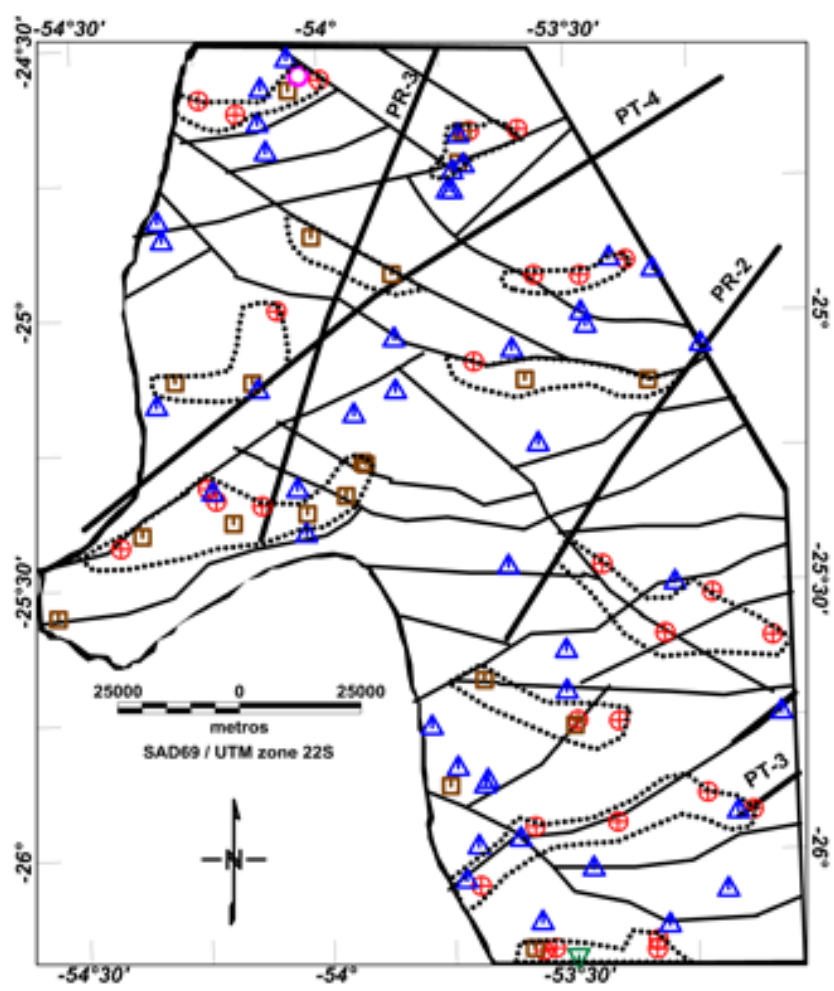

Figura 19 - Mapa de distribuição espacial da composição química das águas da área de estudo. Águas características do SASG: $\triangle$ (bicarbonatadas cálcicas) e $\nabla$ (bicarbonatadas magnesianas). Águas características de conexão hidráulica dos SASG e SAG: $\oplus$ (bicarbonatadas sódicas), (bicarbonatadas mistas), $\bigcirc$ (sulfatadas sódicas).

suas elevações variam de 218,58 a 617,00 m.

Águas bicarbonatadas magnesianas e sulfatadas sódicas representam, respectivamente, apenas $1 \%$ do total de amostras.

A composição química típica das águas do
SASG deve refletir a tipologia da Formação Serra Geral. Visando reconhecer as variações nos teores de elementos alcalinos e alcalino-terrosos em águas do SASG, foram avaliados dados geoquímicos de 54 amostras de rochas basálticas inseridas na área do projeto e cedidas pela Mineropar. Considerando que os óxidos $\mathrm{MgO}, \mathrm{CaO}, \mathrm{K}_{2} \mathrm{O}$ e $\mathrm{Na}_{2} \mathrm{O}$ são os que influenciam diretamente a composição das águas, os mesmos foram selecionados, recalculados em relação aos percentuais totais e plotados no diagrama triangular da figura 18 , a qual reflete a composição média dos basaltos (e.g. Piccirillo \& Melfi 1988). A ausência de teores significativos de $\mathrm{K}_{2} \mathrm{O}$ e $\mathrm{Na}_{2} \mathrm{O}$ na figura 18 faz supor que as águas bicarbonatadas sódicas, mistas e sulfatadas sódicas, detectadas no SASG, podem refletir prioritariamente zonas de conexão hidráulica com aqüíferos sotopostos, principalmente o SAG, e, subordinadamente, envolver elementos provenientes dos basaltos em equilíbrio com minerais secundários.

Finalmente, a figura 19 sintetiza as informações obtidas nesta pesquisa mostrando as composições químicas das águas e as possíveis zonas de conectividade hidráulica dos SASG e SAG (contornos pontilhados). Supõe-se que nestas áreas, localizadas entre importantes estruturas, as composições reflitam um sistema aquífero híbrido, com taxas variadas de mesclagem das águas do SASG e do SAG. As águas deste grupo estão localizadas na porção Sudeste, entre as estruturas PR- 2 e PT- 3, nos quadrantes Nordeste e Noroeste, entre as tendências PR2 e PR- 3 e ao Sul das estruturas PR- 3 e PT- 4, regiões onde há um elevado grau de fraturamento em correspondência a expressivos lineamentos geofísicos.

CONCLUSÕES A interpretação integrada de dados aeromagnéticos, geológicos, de morfoestruturas da rede de drenagem e de imagens orbitais, permitiu definir um arcabouço estrutural caracterizado principalmente por tendências NW-SE e NE-SW, secundariamente E-W e N-S.

A combinação do arcabouço magnético-estrutural regional e dos dados hidrogeológicos e hidroquímicos, oriundos de poços completados na Formação Serra Geral, ensejou avaliar o comportamento das águas subterrâneas no aqüífero homônimo e sugerir relações com sistemas aqǘfferos sotopostos, principalmente o SAG.

A presente investigação procurou demonstrar que parâmetros hidrogeológicos como potenciometria, vazão, capacidade específica de explotação, potencial hidrogeniônico e sólidos totais dissolvidos, estão controlados pela trama estrutural proposta.

O tratamento estatístico dos dados hidroquímicos discriminou cinco grupos, os quais permitiram tecer considerações sobre suas origens e grau de interação rocha/ água. O diagrama de Piper revelou que as composições químicas das águas subterrâneas são preferencialmente bicarbonatadas cálcicas $(47 \%)$, seguida pelas bicarbonatadas sódicas $(30 \%)$, bicarbonatadas mistas $(21 \%)$, bicarbonatadas magnesianas (1\%) e sulfatadas sódicas $(1 \%)$. Em termos gerais, se notou uma pequena variação nos ânions se comparada com a dos cátions, esta última sugestiva da diversidade hidroquímica. A variação nos 
conteúdos de cátions é marcada por uma tendência que evolui de composições bicarbonatadas cálcicas, típicas do SASG, para composições bicarbonatadas sódicas, sendo estas enriquecidas em STD e pH alcalino, provavelmente representando águas de conexão hidráulica.

A ausência de teores significativos de $\mathrm{K}_{2} \mathrm{O}$ e $\mathrm{Na}_{2} \mathrm{O}$ nos basaltos da Formação Serra Geral, a julgar pelos resultados litogeoquímicos, ensejou interpretar as águas bicarbonatadas sódicas, mistas e sulfatadas sódicas, detectadas no SASG, como reflexo de zonas de conectividade com os aqüíferos subbasálticos, principalmente o SAG, e, subordinadamente, envolver elementos provenientes dos basaltos em equilíbrio com minerais secundários.
Agradecimentos Os autores agradecem à CPRM pelos dados aeromagnetométricos, a Suderhsa e a Sanepar pelos dados hidrogeológicos e hidroquimícos e a Mineropar pelos dados litogeoquímicos. Agradecem também aos amigos Marcos Vínicius Delgobo, Fábio Manasses, Fernando Ennes Fridlund, Jeferson Ulisses da Cunha, Luís Gutavo de Castro, Alessandra de Barros e Silva Bongiolo, Viviane Mocellin. Agradecimentos especiais são devidos ao Prof. Dr. Eduardo Chemas Hindi (UFPR) e ao Dr. Edir Ademir Arioli (Mineropar), pelas contribuições e discussões durante o desenvolvimento da pesquisa. F.J.F. Ferreira agradece ao CNPq pela bolsa de Produtividade em Pesquisa.

\section{Referências}

Araújo L.M., França A.B., Potter P.E. 1995. Aqüifero Gigante do Mercosul no Brasil, Argentina, Uruguai e Paraguai: mapas hidrogeológicos das Formações Botucatu, Pirambóia, Rosário do Sul, Buena Vista, Missiones e Taquarembó. Curitiba: UFPR/Petrobrás, 16 p., 9 mapas.

Araújo L.M., França A.B., Potter, P.E. 1999. Hydrogeology of the Mercosul aquifer system in the Paraná and ChacoPraná Basins, South America, and comparison with the Navajo-Nugget aquifer system: Hydrogeology Journal, 7:317-336.

Artur P.C. 1998. Paleolineamentos na Bacia do Paraná: favorabilidade para a acumulação de hidrocarbonetos. São Paulo, Dissertação de Mestrado, Departamento de Geologia, UFPR, 202p.

Bittencourt A.V.L. 1978. Sólidos transportados na bacia hidrográfica do rio Ivaí: aplicação de balanços hidrogeoquímicos na conservação da redução de processos da dinâmica externa. São Paulo, Tese de Doutoramento, Instituto de Geociências, USP, 201p.

Bittencourt A.V.L., Rosa Filho E. F., Hindi E.C., Buchmann Filho A.C. 2003. A influência dos basaltos e de misturas com águas de aqüíferos sotopostos nas águas subterrâneas do Sistema Aqüífero Serra Geral na bacia do rio Piquiri, Paraná - BR. Rev. Águas Subterrâneas, São Paulo, 17:67-76.

Briggs I.C. 1974. Machine contouring using minimum curvature. Geophysics, 39(1):39- 48.

Buchmann Filho A.C. 2002. Características das águas subterrâneas do Sistema Aqüífero Serra Geral no Estado do Paraná. Dissertação de Mestrado, Departamento de Geologia, UFPR, 120p.

Celligoi A. \& Duarte U. 1994. Aspectos hidrogeoquímicos da Formação Serra Geral em Londrina-PR. In: ABAS, Congresso Brasileiro de Águas Subterrâneas, 8, Recife, Anais, p.425-433.

Cordell L. \& Grauch V. 1985. Mapping basement magnetization zones from aeromagnetic data in the San Juan Basin, New México. In: Hinze W. (ed.) Utility of regional gravity and magnetic maps. SEG, p.181-197.

Ferreira F.J.F. 1982a. Alinhamentos estruturais-magnéticos da região centro-oriental da Bacia do Paraná e seu significado tectônico. In: Geologia da Bacia do Paraná:
Reavaliação da potencialidade e prospectividade em hidrocarbonetos. São Paulo, Consórcio CESP-IPT, p.144-166.

Ferreira F.J.F. 1982b. Integração de dados aeromagnéticos e geológicos: configuração e evolução tectônica do Arco de Ponta Grossa. São Paulo, Dissertação de Mestrado, Instituto de Geociências, USP, 174p.

Ferreira F.J.F., Portela Filho C.V., Rosa Filho E.F., Rostirolla S.P. 2004. Connection of the Serra Geral and Guarani aquifers systems across Ponta Grossa Arch (Paraná Basin, Brazil). In: Internacional Congress of the International Association of Hydrogeologists (IAH), 33 and International Congress of the Latin-American Association of Underground Hydrology for Development (ALHSUD), 7, Zacatecas, México, Abstract (CD ROM).

Ferreira F.J.F. \& Abram M.B. 2005. Geofísica. In: Wildner W., Correia de Brito R.S., Licht O.A.B., Arioli E.E. (coords.) Geologia e recursos minerais do sudoeste do Estado do Paraná. Brasília, CPRM (Convênio CPRM/ MINEROPAR - Programa Integração, Atualização e Difusão da Geologia do Brasil), 95p.

Ferreira F.J.F., Portela Filho C.V., Rosa Filho E.F., Rostirolla S.P. 2005. Conectividade e compartimentação dos sistemas aqüíferos Serra Geral e Guarani na região central do Arco de Ponta Grossa (Bacia do Paraná, Brasil). Revista Latino-Americana de Hidrogeologia, 5:61-74.

Fraga C.G. 1986. Introdução ao zoneamento do Sistema Aqüifero Serra Geral no Estado do Paraná. Dissertação de Mestrado, Instituto de Geociências, USP, 125 p.

Fúlfaro V.J., Saad A.R., Santos M.V., Vianna R.B. 1982. Compartimentação e evolução tectônica da Bacia do Paraná. In: Geologia da Bacia do Paraná: Reavaliação da potencialidade e prospectividade em hidrocarbonetos. São Paulo, Consórcio CESP-IPT, p.75-115.

Kittl S. T. 2000. Contributions to the konowledge on the stratigraphy and hydrochemistry of the Giant Guarani Aquifer System, South America. Master Thesis, Universitat $\mathrm{Zu}$ Tubingen, 237p.

Milani E.J. 1997. Evolução tectono-estratigráfica da Bacia do Paraná e seu relacionamento com a geodinâmica fanerozóica do Gondwana sul-ocidental. Tese de 
Doutoramento, Universidade Federal do Rio Grande do Sul, Porto Alegre, 254p.

Milani E.J. \& Ramos V.A. 1998. Orogenias paleozóicas no domínio sul-ocidental do Gondwana e os ciclos de subsidência da Bacia do Paraná. Rev. Bras. Geoc., 28:473-484.

Miller H.G. \& Singh V. 1994. Potential field tilt - a new concept for location of potential field sources. Journal of Applied Geophysics, 32:213-217.

Minty B.R.S. 1991. Enhancement and presentation of airborne geophysical data. AGSO Journal, 17:63-75.

Nabighian M.N. 1972. The analytic signal of two-dimensional magnetic bodies with polygonal cross-section: its properties and use for automated anomaly interpretation. Geophysics, 37:507-517.

Piccirillo E.M. \& Melfi A.J. (eds.) 1988. The Mesozoic flood volcanism of the Paraná Basin - petrogenetic and geophysical aspects. Instituto Astronômico e Geofísico da Universidade de São Paulo, USP, 600p.

Portela Filho C.V., Ferreira F.J.F. Rosa Filho E.F., Rostirolla S.P. 2005. Compartimentação magnética-estrutural do Sistema Aqüífero Serra Geral e sua conectividade com o Sistema Aqüífero Guarani na região central do Arco de Ponta Grossa (Bacia do Paraná). Rev. Bras. Geoc., 35:369-381.

Rebouças A.C. 1978. Potencialidades hidrogeológicas dos basaltos da Bacia do Paraná. In: SBG, Cong. Bras. Geol., 30, Anais, p.1963-1976.

Rebouças A.C. \& Fraga C.G. 1988. Hidrogeologia das rochas vulcânicas do Brasil. Revista de Águas Subterrâneas, ABAS, 12:29-55.

Rebouças A.C., Braga B., Tundisi J.G. 2002. Águas Doces no Brasil-capital ecológico, uso e conservação, $2^{\mathrm{a}}$ ed. São Paulo, Escrituras Editora, 703p.

Rocha G. 1997. O grande manancial do Cone Sul. Estudos Avançados, USP, 30:191-212.

Rosa Filho E.F., Salamuni R., Bittencourt A.V.L. 1987. Contribuição ao estudo das águas subterrâneas nos basaltos do Estado do Paraná. Boletim Paranaense de Geociências, 37:22-52.

Rosa Filho E.F., Hindi E.C., Rostirolla S.P., Ferreira F.J.F., Bittencourt A.V.L. 2003. Sistema Aqüífero Guarani Considerações preliminares sobre a influência do Arco de Ponta Grossa no fluxo das águas subterrâneas. Revista Águas Subterrâneas, 17:91-111.

Rostirolla S.P., Assine M.L., Fernandes L.A., Artur P.C. 2000. Reativação de paleolineamentos durante a evolução da Bacia do Paraná: o exemplo do Alto Estrutural de Quatiguá. Rev. Bras. Geoc., 30:639-648.

Silva A.B. 2007. Conectividade e compartimentação magnética-estrutural dos sistemas aqǘferos Serra Geral e Guarani na região central do Estado do Paraná. Dissertação de Mestrado, Departamento de Geologia, Universidade Federal do Paraná, 147p.

Soares P.C. 1991. Tectônica sinsedimentar cíclica na Bacia do Paraná: controles. Tese de Professor Titular, Universidade Federal do Paraná, 148p.

Soares P.C., Barcellos P.E., Csordas S.M., Mattos J.T., Ballieiro M.G. Meneses P.R. 1982. Lineamentos em imagens de Landsat e radar e suas implicações no conhecimento tectônico da Bacia do Paraná. In: INPE, Simpósio de Sensoriamento Remoto, 2, Brasília, Atas, 2:143-156.

Sracek O. \& Hirata R. 2002. Geochemical and stable isotopic evolution of the Guarani Aquifer System in the state of São Paulo, Brazil. Hydrogeology Journal, 10:643-655.

Strugale M., Rostirolla S.P., Mancini F., Portela Filho C.V., Ferreira F.J.F., Freitas R.C. 2007. Structural framework and Mesozoic-Cenozoic evolution of the Ponta Grossa Arch, Paraná Basin, southern Brazil. Journal of South American Earth Sciences, 2:203-227.

Turner S., Regelous M., Kelley S., Hawkesworth S.E., Mantovani M.M.S. 1994. Magmatism and continental break-up in the South Atlantic: high precision ${ }^{40} \mathrm{Ar}-{ }^{39} \mathrm{Ar}$ geochronology. Earth Planet. Sci. Let., 124:333-348.

Verduzco B., Fairhead C., Green C., Mackenzie C. 2004. New insights into magnetic derivatives for structural mapping. The Leading Edge, 23:116-119.

Zalán P.V., Wolff S., Conceição J.C.J., Astolfi M.A.M., Vieira I.S., Appi V.T., Zanotto O.A. 1987. Tectônica e sedimentação da Bacia do Paraná. In: SBG, Simpósio Sul-Brasileiro de Geologia, Curitiba, Atas, 1:441-477.

Zalán P.V., Wolf S., Conceição J.C.J., Astolfi M.A.M., Vieira I.S., Appi V.T., Neto E.V.S., Cerqueira J.R., Marques A. 1991. The Paraná Basin, Brazil. In: Leighton M.W., Kolata D.R., Oltz D.F, Eidel J.J. (eds.) Interior Cratonic Basins. AAPG Memoir, 51:681-708.

Winjs C., Perez C., Kowalczyk P. 2005. Theta Map: Edge detection in magnetic data. Geophysics, 70:L39-L43.

Manuscrito ID 14146

Submetido em 05 de abril de 2009 Aceito em 25 de setembro de 2009 